\title{
Clove Oil Has the Activity to Inhibit Middle, Maturation and Degradation Phase of Candida Tropicalis Biofilm Formation
}

\author{
Hasyrul Hamzah ${ }^{1}$, Indra Yudhawan ${ }^{2}$, Nur Rasdianah ${ }^{3}$, Endang Setyowati ${ }^{4}$, Erika Nandini ${ }^{1}$, Sylvia Utami \\ Tunjung Pratiwi 5
}

1 Faculty of Pharmacy; Universitas Muhammadiyah Kalimantan Timur; Samarinda, Kalimantan Timur 75124; Indonesia; hh241@umkt.ac.id (H.H.) ; erikanandini2019@gmail.com (E.N.);

2 Department of Pharmacy; Stikes Muhammadiyah Gombong; Jl. Yos Sudarso No. 461; Gombong 54411; Indonesia; indrayudhawan@gmail.com (I.Y.);

3 Pharmacy Study Program; Faculty of Health and Sports; Universitas Negeri Gorontalo; Gorontalo 96128, Indonesia 96128; Indonesia; nr.apoteker@gmail.com (N.A.);

4 Faculty of Health Science, Pharmacy Study Program; Universitas Muhammadiyah Kudus, Jawa Tengah 59316, Indonesia; setyowatiendangapt@gmail.com (E.S.);

5 Department of Pharmaceutical Biology; Faculty of Pharmacy; Universitas Gadjah Mada; Sekip Utara Yogyakarta 55281; Indonesia; Sylvia_pratiwi@ugm.ac.id (S.U.T.P.);

* Correspondence: Sylvia_pratiwi@ugm.ac.id (S.U.T.P.);

Scopus Author ID 56610218800

Received: 29.04.2021; Revised: 28.05.2021; Accepted: 1.06.2021; Published: 9.06.2021

\begin{abstract}
Clove oil is one of the natural antibacterial ingredients that is easily obtained because of its abundant amounts in nature. Various researches have been conducted, but the antibiofilm activity against Candida tropicalis has never been done. This study evaluates the effectiveness of clove oil in inhibiting and degrading C. tropicalis JFM 1541 biofilm activity. The research was conducted using the microtiter broth method. The antibiofilm activity was determined as the minimum biofilm inhibitory concentration $\left(\mathrm{MBIC}_{50}\right)$, the minimum value of biofilm eradication concentration $\left(\mathrm{MBEC}_{50}\right)$. Antibiofilm mechanism was elucidated using scanning electron microscopy (SEM). Statistical analyzes were performed using ANOVA ( $\mathrm{p}<0.05)$. Showed that clove oil could inhibit biofilm formation at the middle phase by $65 \%(65.21 \pm 0.01)$ and at the maturation phase by $56 \%(56.11 \pm 0.01)$. Clove oil with a concentration of $1 \% \mathrm{v} / \mathrm{v}$ has been shown to have activity in degrading $41 \%$ of $C$. tropicalis biofilms $(41.87 \pm 0.01)$. SEM shows that clove oil can cause damage in the extracellular polymeric matrix (EPS) of $C$. tropicalis biofilm. In conclusion, clove oil acts as a potential antibiofilm activity against C. tropicalis (compared to nystatin as control drugs) and further developed a new antibiofilm agent.
\end{abstract}

Keywords: antibiofilm; biofilm; Candida tropicalis; clove oil; Scanning Electron Microscopy (SEM).

(C) 2021 by the authors. This article is an open-access article distributed under the terms and conditions of the Creative Commons Attribution (CC BY) license (https://creativecommons.org/licenses/by/4.0/).

\section{Introduction}

Biofilms are heterogeneous communities of microorganisms that attach to abiotic or biotic surfaces. Some cells will be bonded and attached to a substrate and encased in an extracellular polymeric substance (EPS) matrix to form a complex structure[1,2]. Biofilms communities of microbes adhere to a surface and are embedded within an extracellular matrix comprised of polysaccharides, proteins, and extracellular DNA [3]. Biofilm communities can be formed by one type of microorganism, but biofilms found in nature tend to be in the form of a mixture of various species of bacteria, fungi, algae, and yeast, along with foreign 
substances [4,5]. The specific structure and nature of biofilms stimulate a constant up-and down-regulation of certain genes, followed by metabolism reduction and diversification of bacterial cells functioning [6].

Biofilm is one of many factors that is often causing a problem in the treatment of infections. Biofilm-related problems are often found in cases of infected chronic wounds and the use of implanted medical devices such as catheters and endotracheal tubes $[7,8]$. The characteristic of all these infections caused by bacteria-resistant bacteria is the antibiotics' inability to penetrate the pathogen due to the biofilm structure [9]. Microbes in biofilm states are a major concern since they are much more tolerant to antibiotics and disinfectants in this conformation than in a planktonic state [10].

Candida species are the $2^{\text {nd }}$ most common causative specialists of parasitic diseases worldwide and positioned 5th among hospital-acquired pathogens [11]. C. tropicalis is one of the types/variants of Candida that is commonly found as a cause of human disease in tropical countries. C. tropicalis is very virulent in neutropenic hosts with hematogenous seeding to peripheral organs [12]. C. tropicalis is exceedingly predominant in tropical nations and mindful for lifted mortality rates due to candidiasis [13] A few routine antimicrobial hold potent antibiofilm activity on early-biofilm formation but fail to inhibit mature biofilm on C. tropicalis [14]. C. tropicalis has been shown to cause biofilms and is often found on some abiotic surfaces, including medical devices [15]. The structure and composition of Candida biofilm can vary according to various environmental conditions [16]. However, biofilms of Candida species normally comprise matrix-enclosed microcolonies of yeasts and hyphae and are safe to a few of the antifungal specialists as of now in clinical utilize [17]. Although species of this genus may live as members of the microbiota in healthy individuals, they may cause lifethreatening infections in hospitalized [18]

Indonesia has a high diversity and many plant sources. People often use their knowledge to use medicinal plants instead of modern medicines to maintain health and treat diseases [19]. Clove (SyzygiumAromaticum or Eugenia Aromatucum) is among the plants which are popular in Indonesia. It is a scented dried flower stalk from the tree family Myrtaceae. The activity of basic oils, due to their complexity, is as a rule considered as a synergistic impact of several fundamental compounds [20]. Clove oil has many biological activities, including antibacterial [21,22], antifungal [23], antioxidant [24,25], antipathogenic [26], antiviral, anticarcinogenic [27], antitumor agent [28] and traditionally used as a flavouring agent and also and food preservative [23]. Clove oil mainly consisted of eugenol as its main component (60-90\%) [29-31]. In some cases related to bud maturity, eugenol content can reach up to $90-94 \%$ [32].

Research on clove oil as an antibacterial has not been done a lot. Mainly, the research focus on its main component, eugenol. Eugenol has proven to have a wide range of antibacterial activities, including activities against Escherichia coli, Staphylococcus aureus, Pseudomonas aeruginosa [33], Listeria monocytogenes [34], Salmonella typhi [35], Streptococcus mutans [36].In addition to the genus Candida, eugenol has activity against $C$. albicans, $C$. dubliniensis, C. glabrata, C. guilliermondii, C. krusei, C. parapsilosis, and C. tropicalis cells [37-39]. Several studies have shown that eugenol has antibiofilm activity against $S$. maltophilia [40], $P$. gingivalis [41], S. enteritidis, S. typhimurium [42]

The activity of clove oil in inhibiting the formation of biofilms caused by $C$. Tropicalis bacteria was not fully known. This study evaluates the antibiofilm activity of clove oil against C. Tropicalis bacteria in the middle, maturation, and degradation phase of biofilm formations. 


\section{Materials and Methods}

\subsection{Instruments.}

Laminar Discuss Stream, hatchery (IF-2B) (Sakura, Japan), micropipette pipetman (Gilson, France), multichannel micropipette (Socorex, Swiss), microplate flat-bottom polystyrene 96 well (Iwaki, Japan), microtiter plate peruser (Optic Ivymen Framework 2100C, Spain), spectrophotometer (Genesys 10 UV Filtering, 335903) (Thermo Logical Spectronic, USA), autoclave (Sakura, Japan), expository scale (AB204 -5, Switzerland).

\subsection{Materials.}

The materials used in this study were clove oil, isolates of $C$. tropicalis which form biofilm standards (C. tropicalis JFM 1541) from microbiology laboratory collections of UGM Faculty of Medicine, Nystatin, DMSO 1\%, NaCl, Mc Farland Standard 0.5, sterile distilled water, SDA (Sabaroud Dextrose Agar) media, RPMI media, PBS solution (Phosphate Buffer Saline), violet crystal $1 \%$, disposable gloves and mask.

\subsection{Preparation of fungi for assay.}

The isolate tested in the study was $C$. tropicalis JFM 1541. Several fungal colonies were inoculated from the SDA media into $15 \mathrm{~mL}$ of YPD medium and then incubated at room temperature while in the shaker overnight. It centrifuged for 15 minutes at $3000 \mathrm{rpm}$ and washed with PBS. The pellets obtained were resuspended with RPMI medium, and a $1 \times 10^{8}$ $\mathrm{CFU} / \mathrm{mL}$ C. tropicalis suspension was made in $5 \mathrm{~mL}$ RPMI medium (likened to the Mc Farland standard 0.5). $1 \mathrm{~mL}$ was taken from this suspension and added to $9 \mathrm{~mL}$ of RPMI medium to obtain a $C$. tropicalis colony suspension of $1 \times 10^{7} \mathrm{CFU} / \mathrm{mL}$ as a stock solution. The working solution was made with a 1:10 dilution to obtain a $1 \times 10^{6} \mathrm{CFU} / \mathrm{mL}$ C. tropicalis suspension [43].

\subsection{Determination of minimum biofilm inhibitory concentration (MBIC) using microbroth} dilution method.

The effects of clove oil were examined on the strain C. tropicalis JFM 1541 biofilm. The biofilm was inoculated in a 96-well flat-bottom polystyrene flat plate microtiter. A total of $200 \mu \mathrm{L}$ of $C$. tropicalis suspension $\left(10^{6} \mathrm{CFU} / \mathrm{mL}\right)$ was added to each microtiter plate wells then incubated at $\pm 37^{\circ} \mathrm{C}$ for 90 minutes [44]. After the incubation period, the plates are washed with PBS. A total of $200 \mu \mathrm{L}$ of media containing pure isolates with a series of concentrations $(1 \% \mathrm{v} / \mathrm{v}-0.125 \% \mathrm{v} / \mathrm{v})$, were added to each well that had been washed. Media containing $1 \%$ DMSO were used as solvent control, and the microbial suspension was used as a negative control. The microbial suspension was added with antifungal nystatin levels of $1 \% \mathrm{v} / \mathrm{v}$ as a positive control, and media control was media without added microbial [45].

The plates were then incubated at $37^{\circ} \mathrm{C}$ for 24 hours for biofilm formation in the midphase and 48 hours for the maturation phase $[46,47]$. Then the plate is washed using PBS. A total of $125 \mu \mathrm{L}$ of $1 \%$ violet crystal solution was added to each well. Then it was incubated at room temperature for 15 minutes. After incubation, the microplate was washed with PBS and added $200 \mu \mathrm{L}$ of $96 \%$ ethanol to each well to dissolve the biofilm formed. Optical Density (OD) readings are carried out with a microplate reader at a wavelength of $595 \mathrm{~nm}$. 


\subsection{Determination of minimum biofilm reduction concentration (MBRC).}

The effects of clove oil were also examined on the strain C. tropicalis JFM 1541 biofilm using the earlier method [48]. Biofilms are inoculated in microtiter like those described above. After brooding at $37^{\circ} \mathrm{C}$ for 48 hours, the culture supernatant from each well was tapped, and the planktonic cells were evacuated by washing with PBS. Biofilm cells were exposed to various concentrations of clove oil, ranging from $1 \% \mathrm{v} / \mathrm{v}$ to $0.125 \% \mathrm{v} / \mathrm{v}$, and then incubated at $37^{\circ} \mathrm{C}$ for 48 hours. Nystatin at a concentration of $1 \% \mathrm{v} / \mathrm{v}$ was used as a positive control. After incubation, the plates are washed three times with $200 \mathrm{~mL}$ of sterile PBS to remove the attached cells. Biofilm degradation was quantified with $125 \mu \mathrm{L}$ of $1 \%$ violet crystal solution into each well, subsequently incubated at room temperature for 15 minutes. After incubation, the microplate was washed with PBS and added $200 \mu \mathrm{L}$ of $96 \%$ ethanol to each well to dissolve the biofilm formed. Optical Density (OD) readings are carried out with a microplate reader at a wavelength of $595 \mathrm{~nm}$ [49].

\subsection{Scanning electron microscopy (SEM).}

The coverslip was embedded interior the microtiter plate circular foot polystyrene 24 well that contained testing suspension that had been given a comparable treatment with biofilm restraint test. The coverslips were at that point hatched at $37^{\circ} \mathrm{C}$ for $24-48$ hours, continued to the careful washing of the coverslip for three-time with sterile aqua dest, then fixated with 0.5 $\%(\mathrm{v} / \mathrm{v})$ glutaraldehyde interior cacodylate buffer for \pm 24 hours with the point of cell's passing without changing the cell's structure that will be watched. Another, a lack of hydration handle utilizing methanol was done for 30 minutes to play down the water sum so that the watching preparation seemed not hindered. The test at that point watched using SEM with a voltage of $10 \mathrm{kV}[50]$

\subsection{Statistical methods.}

Statistical analysis was performed using ANOVA and Normality test performed using the Shapiro - Wilk, with p values of 0.05 or less. The data were analyzed using the Statistical Package for the Social Sciences (SPSS).

\section{Results and Discussion}

Table 1. MBIC50 value of clove oil against mono-species $C$. tropicalis at all biofilm growth phase (ANOVA

\begin{tabular}{c|c|c|c}
\multirow{2}{*}{ Compound } & $\begin{array}{c}\text { MBIC } 50 \% \mathrm{v} / \mathrm{v} \\
\text { Middle phase (24h) }\end{array}$ & $\begin{array}{c}\text { with } p<0.05) . \\
\text { Maturationphase (48h) }\end{array}$ & $\begin{array}{c}\text { MBEC }_{50 \% \mathrm{v} / \mathrm{v}} \\
\text { Degradationphase }\end{array}$ \\
\hline Clove Oil & $0.25 \% *$ & $0.5 \% *$ & $1 \% *$
\end{tabular}

3.1. Effect of clove oil against biofilms of mono-species C. tropicalis at the middle phase $(24 h)$.

We evaluate the antibiofilm potency of clove oil against biofilm of mono-species $C$. tropicalis. Our finding showed that clove oil has an inhibitory activity of $50 \%$ against $C$. tropicalis biofilm in the middle phase (Figure 1). 


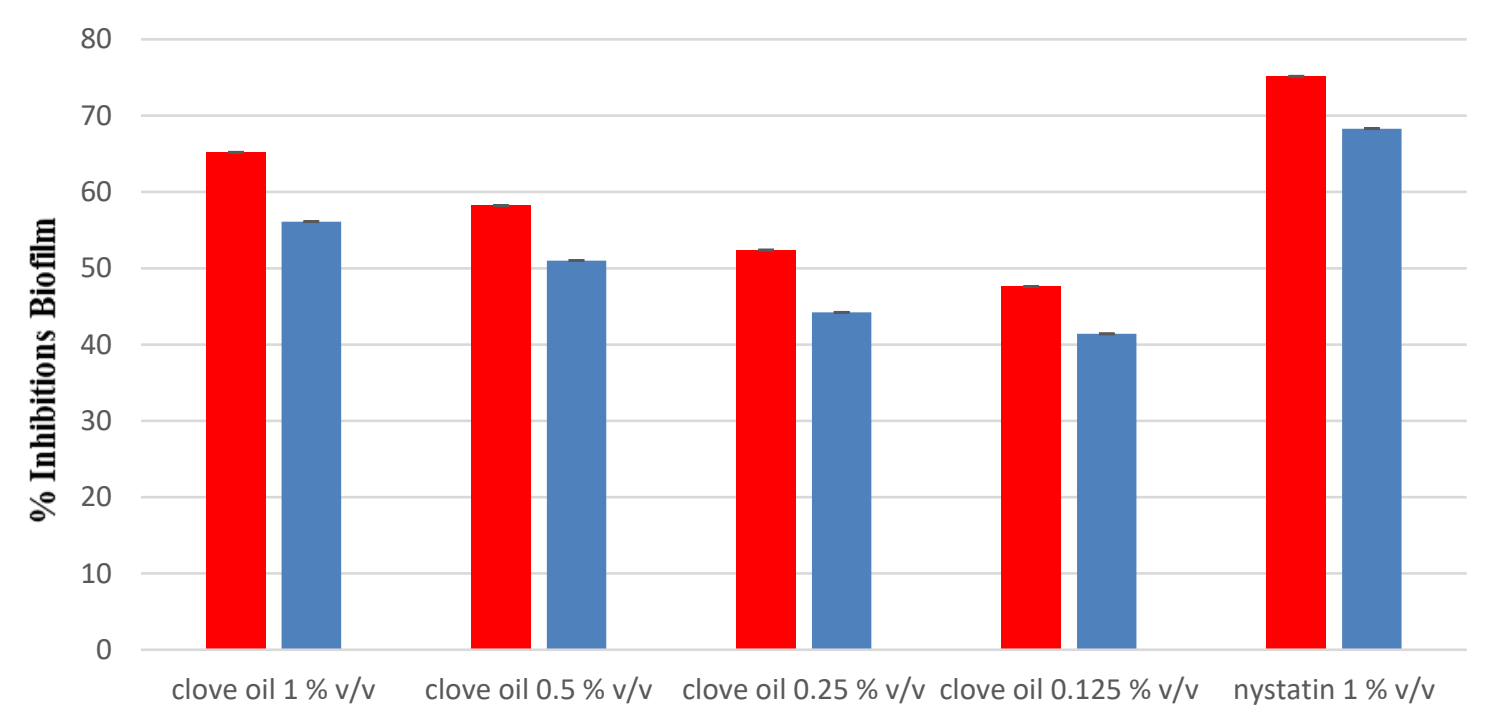

Concentration

Figure 1. Inhibition percentage of clove oil on C. tropicalis mono-species biofilm. (red bar: middle-phase, blue bar: maturation-phase, ANOVA with $p<0.05$ ).

The biofilm inhibition from clove oil was $65.21 \pm 0,01$, and the effect is similar to the nystatin as the control groups $(75.17 \pm 0.01)$. MBIC 50 activity of clove oil is around $0.25 \% \mathrm{v} / \mathrm{v}$ $(* P<0.05)$. This result proves that clove oil could inhibit biofilm formation before $C$. tropicalis entering phase-3 on biofilm formation (Table 1).

\subsection{Effect of clove oil against biofilms of mono-species $C$. tropicalis at maturation phase} $(48 h)$.

The results showed that, at the maturation phase, clove oil has an inhibitory activity of $56.11 \pm 0.01$ while nystatin was $68.29 \pm 0.01$ (Figure 1 ) at $1 \% \mathrm{v} / \mathrm{v}$ concentration. The reduction of nystatin and clove oil inhibitory activity against $C$. tropicalis, compared to the middle phase, is due to the formation of $C$. tropicalis biofilms with a more complex structure. In this phase, the growth time of $C$. tropicalis biofilm is longer than in the middle phase. Also, normally a thick EPS matrix has formed, and inter-cell communication (quorum sensing) has occurred.

Even though the clove oil activity had decreased at the maturation phase, the MBIC 50 activity of clove oil was at $0.5 \% \mathrm{v} / \mathrm{v}(* P<0.05)$ (Table 1$)$. This shows that clove oil still has sufficient potential to be developed as an antibiofilm agent for the maturation phase of biofilms.

\subsection{Effect of clove oil against biofilms of mono-species $C$. tropicalis at degradation phase.}

The results showed that at the degradation phase, clove oil with a concentration of $1 \%$ $\mathrm{v} / \mathrm{v}$ gave the inhibitory activity of the biofilms of $41.87 \pm 0.01$, while nystatin was $56.10 \pm 0.01$. There was a decrease in biofilm inhibitory activity compared to the middle phase $(65.21 \pm 0.01)$ and maturation phase $(50.11 \pm 0.01)(* P<0.05)$ (Figure 2$)$. 


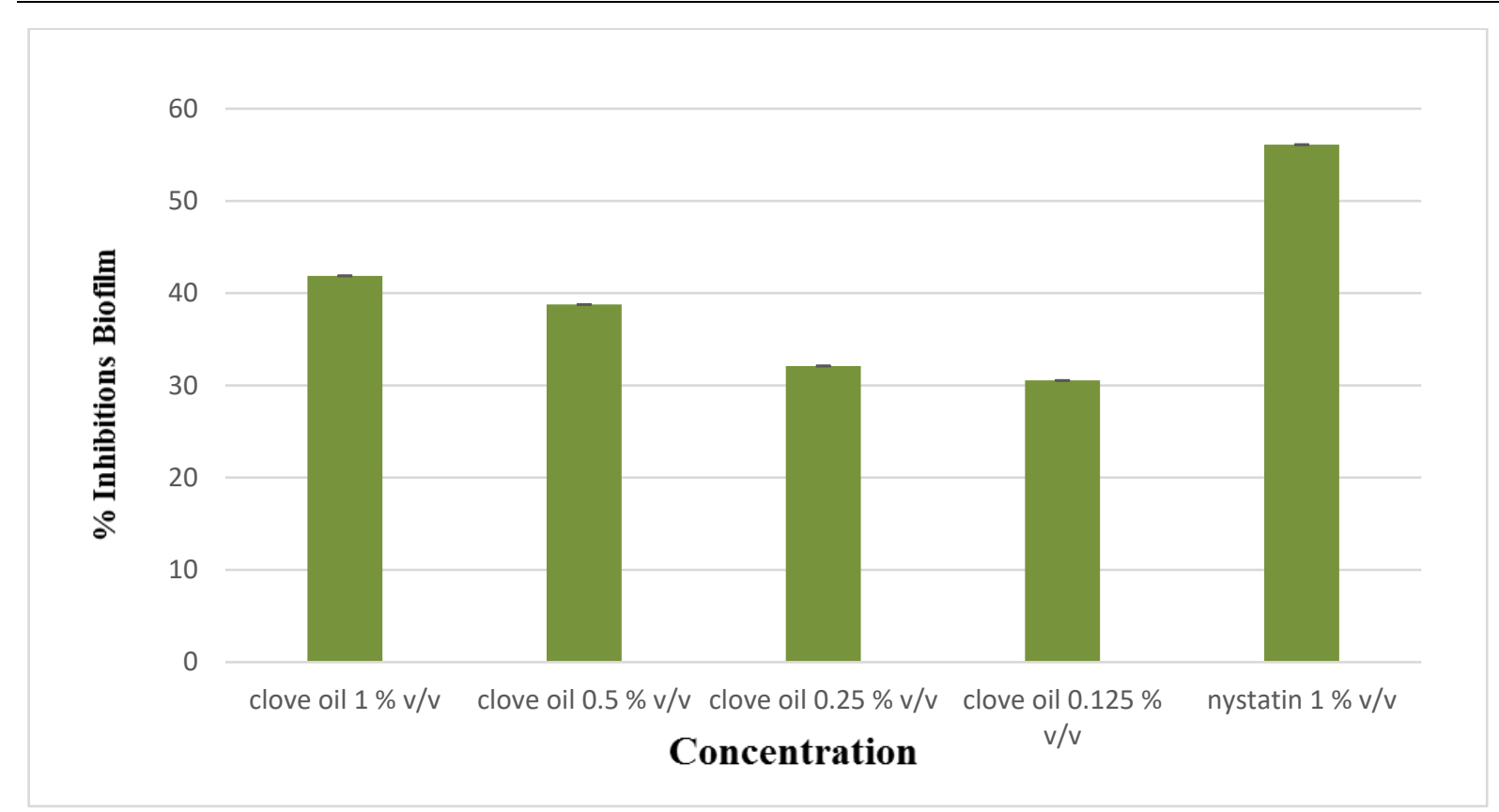

Figure 2. Inhibitory effect of clove oil against $C$. tropicalis biofilm at degradation phase (ANOVA with $p$ $<0.05)$.

The Biofilm degradation phase is the longest phase in biofilm formation. This phase is different from the middle phase and maturation. In this phase, EPS biofilm structure is wellformed, thicker, and very complex so that the protection of bacteria from antimicrobial agents and antibiofilm becomes stronger [5].

\subsection{Scanning electron micrograph (SEM) result of untreated C. tropicalis biofilm.}

The result showed that untreated $C$. tropicalis has a high cell density on the EPS Matrix which is protected C. tropicalis (Figure 3). This indicated that biofilm was formed.

Biofilms matrix serves as a link between adhesive and cohesive interactions providing mechanical stability to biofilms, control cell dispersion from biofilms, and could also act as providers of nutritional sources for cell communication [51]. The biofilm matrix of C. albicans is also acted as a protective biofilm cell and as a major barrier protecting biofilm cells during the attack from the immune system and treatment of antifungal drugs.

According to Al Fattani and Douglas (2006), the matrix from C. tropicalis biofilm mostly composed of hexosamine $(27.4 \%)$ with some smaller carbohydrate $(3.3 \%$, including $0.5 \%$ glucose), protein (3.3\%), and phosphor $(0.2 \%)$ [52]

\subsection{Scanning electron microscopy (SEM) result of C. tropicalis administrated by $0.5 \% \mathrm{v} / \mathrm{v}$} clove oil.

Clove oil $0.5 \% \mathrm{v} / \mathrm{v}$ can cause $C$. tropicalis biofilms cells to become lysis and cell density decreases (Figure 3).

The picture from SEM (figure 3) shows that the administration of clove oil is proven to be able to damage the bacteria because the active compound can attack the EPS matrix of $C$. tropicalis. The findings show that clove oil can damage the cells and preventing $C$. tropicalis from forming the hyphae. On the other hand, a decline of the cell attachment, cell density, and lysis of the cell were observed. 


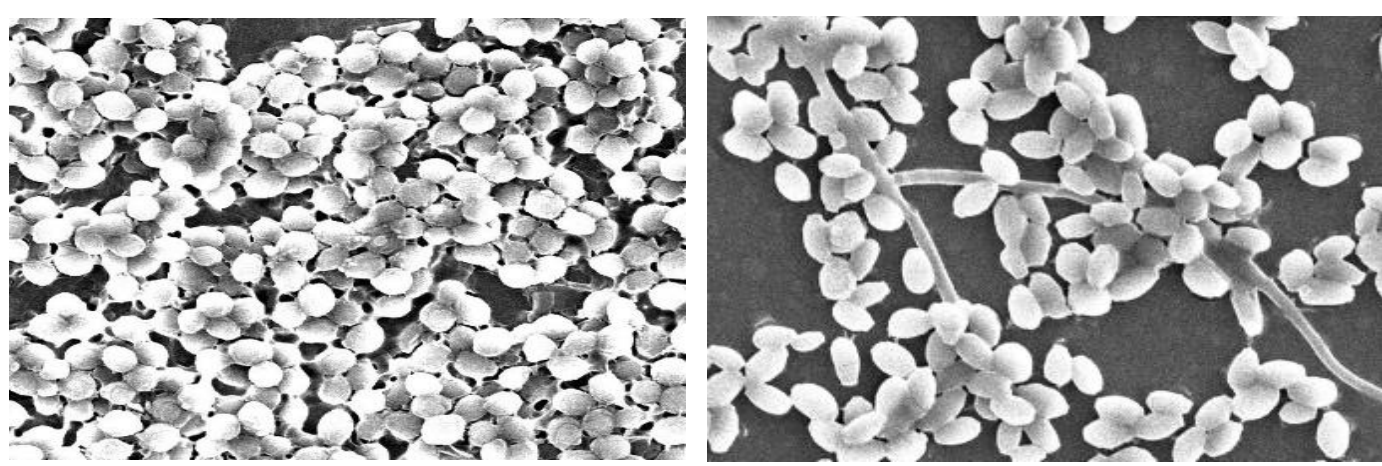

(a)
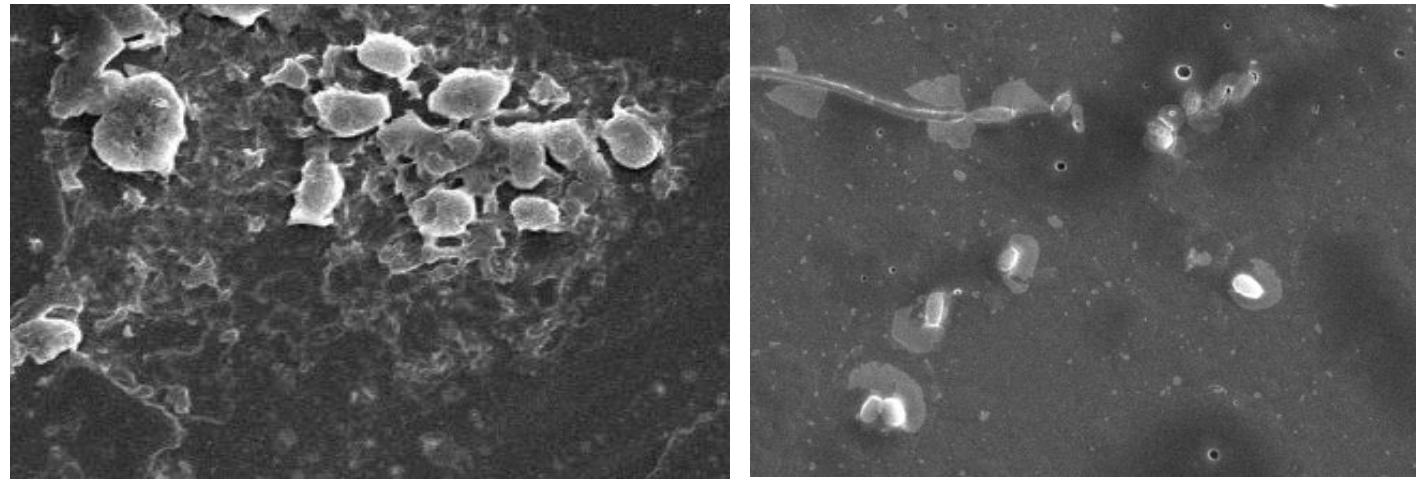

(b)

Figure 3. Scanning Electron Microscopy (SEM) picture of C. tropicalis treated with $0.5 \%$ v/v clove oil, (a) before treatment; (b) after treatment.

\subsection{Discussions.}

This study aims to evaluate the inhibitory activity of clove oil against $C$. tropicalis biofilm formation. The biofilm formation process consists of 5 stages 37 . First, bacteria cells stick to the surface of the substrate because of the influence of Van der Walls forces. In this step, the cell adhesion process is still temporary. Second, bacterial cells have permanently attached to the surface of the substrate because of the formation of exopolymer material which is a stronger adhesive compound. Third, a stage marked by the formation of microcolonies and biofilm begins to form. Fourth, the biofilm formed becomes more abundant and forms a threedimensional structure containing covered cells in several groups connected to each other. Fifth, the last stage, is the development of biofilm structure results in cell dispersion and causing the cell to separate from biofilm, attached to a new substrate and forming a new biofilm, followed by microcolony formation and subsequent growth into mature biofilms with self-production of extracellular polymeric substances (EPS) [53].

The results showed that, in the middle phase, clove oil inhibited $50 \%$ of $C$. tropicalis biofilm formation (Figure1). The inhibition of clove oil against mid-tropical $C$. tropicalis was $65.21 \pm 0.01$ and had a similar activity with nystatin as drug control $(75.17 \pm 0.01)$. MBIC 50 activity of clove oil is $0.25 \% \mathrm{v} / \mathrm{v}$. This proves that clove oil has the activity to inhibit biofilm formation before entering phase 3 in biofilm formation (Table 1).

The process of a compound inhibits the biofilm phase's growth by inhibiting the attachment of microbes to the surface to disrupt the development of biofilms. If the development of biofilms is disrupted, this will affect the biofilm structure to increase its defense against antimicrobials [49]. Bacteria in biofilm forms are different from planktonic bacteria in various ways of growth. One of the consequences is that bacteria in biofilms have been shown to be more resistant to antibiotics and antimicrobials [52]. Increased Candida infections on 
biofilms cause and contribute to high antifungal resistance and escape from host defenses, resulting in persistent infection [54].

Inhibitory activity in the maturation phase was decreased $(56.11 \pm 0.01)$, while the control of nystatin was $68.29 \pm 0.01$. The same thing was also seen in the degradation phase, where clove oil with a concentration of $1 \% \mathrm{v} / \mathrm{v}$ has activity in the degradation phase of 41.87 \pm 0.01 , while nystatin was $56.10 \pm 0.01$. There was a decrease in biofilm inhibitory activity compared to the middle phase $(65.21 \pm 0.01)$ and maturation phase $(56.11 \pm 0.01)(* \mathrm{P}<0.05)$ (Figure 2).

This statement is in line with Hamzah's proposal that in the maturation phase, antimicrobial agents will have more difficulty penetrating the biofilm defenses [55]. Mature biofilms consist of yeast with hyphal elements forming complex tissues encased in the EPS matrix and away from the surface [56].

The degradation phase has a stronger biofilm defense than the maturation phase. In this phase, the EPS matrix composition is very thick and very difficult to be penetrated by antibiofilm agent compounds due to a long time in biofilm growth, so bacteria can meet their nutritional needs.

Microbes that form biofilms in the degradation phase are more difficult to destruct than in the middle and inhibitory phases. This is because the biofilm has grown long enough so that complex biofilm defenses have formed, embedded deeper, and more EPS is produced so that antibiotics are difficult to penetrate. Besides, microbes have also formed quorum sensing communication [45]. This is also consistent with the fact that resistance to antifungals in biofilms is primarily attributed to the extracellular matrix acting as a shield that delays or prevents drug spread to individual cells located deep within the microcolony, thereby reducing adsorption and or neutralizing the effect of the drug [57]

The results showed that clove oil has activity as a middle phase, maturation, and degradation-phase antibiofilm, although the effect decreases along with the longer time/higher phase of biofilm formation. This study doesn't give much information about the mechanism of action of clove oil as antibiofilm. Various works of literature state that the mechanisms of action mediated by clove oil are still being studied. There was not much information known related to the mechanism of clove oil as antibiofilm. Mainly, other researches related to clove oil are conducted based on eugenol as its main component.

Recent research showed that clove essential oil could kill numerous bacteria and fungi, and the antimicrobial activity is attributable to eugenol, oleic acids, and lipids found in its essential oils [58]. Clove fundamental oil (CEO) speaks to one of the EOs with recognized antibacterial movement and wide pertinence in restorative hone for the complementary treatment of contaminations caused by bacteria [59]. Eugenol, the major component of Syzygium aromaticum (clove) oil [60]. There are several mechanisms of eugenol as antibiofilm. Eugenol (and thymol and carvacrol) can inhibit the activity of H+-ATPase and efflux pump. A substantial decrease in C. albicans cell adherence was also observed due to the administration of eugenol [39]. Eugenol can disrupt cell connections, detect existing biofilms, and eradicate bacteria on biofilms, MRSA and MSSA (having the same effectiveness). Eugenol significantly reduced the expression of biofilms and enterotoxin-related genes and decreased bacterial colonization of the middle ear [61]. Eugenol affects suppressing $P$. gingivalis antibiofilm and decreases the expression of genes that encode virulence factors [62]. Eugenol can cause major changes in the morphology of planktonic cells and leakage of cytoplasmic constituents in candida spp., indicating that the mechanism is related to the cell membrane. 
Although the mechanism in eradicating the candida spp. is not yet fully known [63]. Besides, cell membrane damage is also possible due to Reactive Oxygen Species [39].

This finding showed that clove oil is very potential to be developed into an antibiofilm agent. Further research can be conducted in elucidating the composition of clove oil components and the mechanism of action of clove oil or its component as antibiofilm, especially eugenol. Other research can be carried out, including conducting research using other microbial strains or developing more potent clove oil either by finding, isolating, studying and modifying its active component or through formulation with nanomolecular technology to overcome limitations on EPS membranes.

\section{Conclusions}

Clove oil could inhibit the formation of $C$. tropicalis biofilms. Therefore, clove oil is very potential to be developed as $C$. tropicalis antibiofilm. Further research can be carried out, especially in research using other bacterial strains, elucidating the mechanism of action, evaluating its active component, and improvement by formulation in nanomolecular preparation.

\section{Funding}

This research received no external funding.

\section{Acknowledgments}

The author acknowledges Mr. Sutiono, who has been very helpful in preparing clove oil samples.

\section{Conflicts of Interest}

The authors declare no conflict of interest.

\section{References}

1. Anderson, G.G.; Palermo, J.J.; Schilling, J.D.; Roth, R.; Heuser, J.; Hultgren, S.J. Intracellular Bacterial Biofilm-Like Pods in Urinary Tract Infections. Science. 2003, 301, 105-107, https://doi.org/10.1126/science.1084550.

2. Cavalheiro, M.; Teixeira, M.C.; Candida Biofilms: Threats, Challenges, and Promising Strategies. Front. Med 2018, 5, 28, https://doi.org/10.3389/fmed.2018.00028.

3. Tseng, Y. K.; Chen, Y. C.; Hou, C. J.; Deng, F. S.; Liang, S. H.; Hoo, S. Y.; Hsu, C. C.; Ke, C. L.; Lin, C. H. Evaluation of biofilm formation in candida tropicalis using a silicone-based platform with synthetic urine medium. Microorganisms 2020, 8, https://doi.org/10.3390/microorganisms8050660.

4. Chen, M.; Yu, Q.; Sun, H. Novel Strategies for the Prevention and Treatment of Biofilm Related Infections. Int. J. Mol. Sci 2013, 14, 18488-18501, https://doi.org/10.3390/ijms140918488.

5. Pratiwi, S.U.T.; Lagendijk, E.L.; Hertiani, T.; Weert, S.D.; Hondel, C.A.M.J.J. Antimicrobial Effects of Indonesian Medicinal Plants Extracts on Planktonic and Biofilm Growth of Pseudomonas aeruginosa and Staphylococcus aureus. 1., J Horticulture 2015, 2:1

6. DOI: 10.4172/2376-0354.100011 https://doi.org/10.4172/2376-0354.1000119.

7. Tyfa, A.; Laskowski, D.; Kunicka-styczy, A. Alicyclobacillus acidoterrestris Biofilm on. Molecules 2020, 25, 3334, 1-11, https://doi.org/doi:10.3390/molecules25153334.

8. Donlan, R.M. Biofilms: Microbial Life on Surfaces. Emerg. Infect. Dis 2002, 8, 881-890, https://doi.org/10.3201/eid0809.020063. 
9. Harriott, M.M.; Noverr, M.C. Importance of Candida-Bacterial Polymicrobial Biofilms in Disease. Trends Microbiol 2011, 19, 557-563, https://doi.org/10.1016/j.tim.2011.07.004.

10. Talapko, J.; Škrlec, I. The principles, mechanisms, and benefits of unconventional agents in the treatment of biofilm infection. Pharmaceuticals. 2020, 13, 1-13, https://doi.org/10.3390/ph13100299.

11. Aires, A.; Barreto, A. S.; Semedo-Lemsaddek, T. Antimicrobial effects of essential oils on oral microbiota biofilms: The toothbrush in vitro model. Antibiotics. 2021, 10, 1-16, https://doi.org/10.3390/antibiotics10010021.

12. Lone, S. A.; Ahmad, A. Inhibitory effect of novel Eugenol Tosylate Congeners on pathogenicity of Candida albicans. BMC Complementary Medicine and Therapies 2020, 20, 1-14, https://doi.org/10.1186/s12906-02002929-0

13. Chai, L.Y.A.; Denning, D.W.; Warn, P. Candida tropicalis in Human Disease. Crit. Rev. Microbiol. 2010 , 36, 282-298, https://doi.org/10.3109/1040841X.2010.489506.

14. Lemos, A. S. O.; Florêncio, J. R.; Pinto, N. C. C.; Campos, L. M.; Silva, T. P.; Grazul, R. M.; Pinto, P. F.; Tavares, G. D.; Scio, E.; Apolônio, A. C. M.; Melo, R. C. N.; Fabri, R. L. Antifungal Activity of the Natural Coumarin Scopoletin Against Planktonic Cells and Biofilms From a Multidrug-Resistant Candida tropicalis Strain. Frontiers in Microbiology 2020, 11, 1-11, https://doi.org/10.3389/fmicb.2020.01525.

15. Prasath, K. G.; Tharani, H.; Kumar, M. S.; Pandian, S. K. Palmitic Acid Inhibits the Virulence Factors of Candida tropicalis: Biofilms, Cell Surface Hydrophobicity, Ergosterol Biosynthesis, and Enzymatic Activity. Frontiers in Microbiology 2020, 11, 1-21, https://doi.org/10.3389/fmicb.2020.00864.

16. Ramage, G.; Mart Ã-nez, J.P.; LÃ3pez-Ribot, J.L. Candida Biofilms on Implanted Biomaterials: A Clinically Significant Problem. FEMS Yeast Res. 2006, 6, 979-986, https://doi.org/10.1111/j.1567-1364.2006.00117.x.

17. Kıvanç, M.; Er, S. Biofilm formation of candida spp. Isolated from the vagina and antibiofilm activities of lactic acid bacteria on the these candida isolates. African Health Sciences 2020, 20, 641-648, https://doi.org/10.4314/ahs.v20i2.12.

18. Kit, A.; Chan, Y. Aspirin as an Antifungal-Lock Agent in Inhibition of Candidal Biofilm Formation in Surgical Catheters. Infection and Drug Resistance 2021, 2021, 1427-1433, https://doi.org/10.2147/IDR.S308262

19. Tekintaş, Y.; Temel, A.; Ateş, A.; Eraç, B.; Metin, D. Y.; Hilmioğlu Polat, S.; Hoşgör Limoncu, M. Antifungal and antibiofilm activities of selective serotonin reuptake inhibitors alone and in combination with fluconazole. Turkish Journal of Pharmaceutical Sciences 2020, 17, 667-672, https://doi.org/10.4274/tjps.galenos.2019.65481.

20. Nurwijayanto, M.; Wahyuono, S.; Syahbudin, A. Screening of Antioxidants Properties from Understory Plants of Gunung Merapi National Park (Yogyakarta, Indonesia): Potential Use for Alternative Medicine. Ecol. Environ. Conserv. 2019, 25, 1030-1034, https://www.researchgate.net/publication/337159663_ICINE.

21. Katarzyna Rajkowska; Paulina Nowicka-Krawczyk; Alina Kunicka-Styczynska; Cells, Y. Effect of Clove and Thyme Essential Oils on Candida Biofilm Formation and the Oil Distribution in Yeast Cells. Molecules 2019, 1-12, https://doi.org/10.3390/molecules24101954.

22. Blank, G.; Al-Khayat, M.; Ismond, M.A.H. Germination and Heat Resistance of Bacillus subfilis Spores Produced on Clove and Eugenol Based Media. Food Microbiol 1987, 4, 35-42, https://doi.org/10.1016/07400020(87)90016-5.

23. Hoque, M.; Bari, M.L.; Juneja, V.K.; Kawamoto, S. Antimicrobial Activity of Cloves and Cinnamon Extracts Against Food Borne Pathogens and Spoilage Bacteria, and Inactivation of Listeria Monocytogenes in Ground Chicken Meat with Their Essential Oils. Rep Nat'l Food Res Inst 2008, 72, 9-21, https://agris.fao.org/agrissearch/search.do?recordID=JP2008003797.

24. Sulieman, A.M.E.; El Boshra, I.M.O.; El Khalifa, E.A.A. Nutritive Value of Clove (Syzygium aromaticum) and Detection of Antimicrobial Effect of Its Bud Oil. Res. J. Microbiol 2007, 2, 266-271, https://www.researchgate.net/publication/282855327_Nutritive_Value_of_Clove_Syzygium_aromaticum_a nd_Detection_of_Antimicrobial_Effect_of_its_Bud_Oil.

25. Kramer R.E. Antioxidants in Clove. J. Am. Oil Chem. Soc 1985, 62, 111-113, https://doi.org/10.1007/BF02541505.

26. Lee, K.-G.; Shibamoto, T. Antioxidant Property of Aroma Extract Isolated from Clove Buds [Syzygium aromaticum (1.) Merr. Et Perry]. Food Chem 2001, 74, 443-448, https://doi.org/10.1016/S03088146(01)00161-3. 
27. Batiha, G. E. S.; Alkazmi, L. M.; Wasef, L. G.; Beshbishy, A. M.; Nadwa, E. H.; Rashwan, E. K. Syzygium aromaticum 1. (myrtaceae): Traditional uses, bioactive chemical constituents, pharmacological and toxicological activities. Biomolecules 2020, 10, https://doi.org/10.3390/biom10020202.

28. Husain, F. M.; Ahmad, I.; Asif, M.; Tahseen, Q. Influence of clove oil on certain quorum-sensing-regulated functions and biofilm of Pseudomonas aeruginosa and Aeromonas hydrophila. Journal of Biosciences 2013, 38, 835-844, https://doi.org/10.1007/s12038-013-9385-9.

29. da Costa, J. S.; Barroso, A. S.; Mourão, R. H. V.; da Silva, J. K. R.; Maia, J. G. S.; Figueiredo, P. L. B. Seasonal and antioxidant evaluation of essential oil from Eugenia uniflora L., curzerene-rich, thermally produced in situ. Biomolecules 2020, 10, https://doi.org/10.3390/biom10020328.

30. Alma, M.H.; Ertas, M.; Nitz, S.; Kollmannsberger, H. Chemical Composition and Content of Essential Oil. Bioresources $\quad \mathbf{2 0 0 7}, 265-269$, https://www.researchgate.net/publication/26460126_Chemical_composition_and_content_of_essential_oil_ from_the_bud_of_cultivated_Turkish_clove_Syzygium_aromaticum_L.

31. Alma, M.H.; Ertas, M.; Nitz, S.; Kollmannsberger, H. Chemical Composition and Content of Essential Oil. Bioresources $\quad \mathbf{2 0 0 7}, 265-269$, https://www.researchgate.net/publication/26460126_Chemical_composition_and_content_of_essential_oil_ from_the_bud_of_cultivated_Turkish_clove_Syzygium_aromaticum_L.

32. Amelia, B.; Saepudin, E.; Cahyana, A.H.; Rahayu, D.U.; Sulistyoningrum, A.S.; Haib, J. GC-MS Analysis of Clove (Syzygium aromaticum) Bud Essential Oil from Java and Manado. AIP Conference Proceedings 2017, https://doi.org/10.1063/1.4991186.

33. Nurdjannah, N.; Bermawie, N.; Cloves. In. Handbook of Herbs and Spices. Woodhead Publishing Limited 2012, 197-215, https://doi.org/10.1533/9780857095671.197.

34. Walsh, S.E.; Maillard, J.-Y.; Russell, A.D.; Catrenich, C.E.; Charbonneau, D.L.; Bartolo, R.G. Activity and Mechanisms of Action of Selected Biocidal Agents on Gram-Positive and -Negative Bacteria. J. Appl. Microbiol 2003, 94, 240-247, https://doi.org/10.1046/j.1365-2672.2003.01825.x.

35. Filgueiras, C.T.; Vanetti, M.C.D. Effect of Eugenol on Growth and Listeriolysin O Production by Listeria monocytogenes. Braz. Arch. Biol. Technol 2006, 49, 405-409, https://doi.org/10.1590/S151689132006000400008.

36. Devi, K.P.; Nisha, S.A.; Sakthivel, R.; Pandian, S.K.. Eugenol (an Essential Oil of Clove) Acts as an Antibacterial Agent Against Salmonella typhi by Disrupting the Cellular Membrane. J. Ethnopharmacol 2010, 130, 107-115, https://doi.org/10.1016/j.jep.2010.04.025.

37. Jafri, H.; Banerjee, G.; Khan, M. S. A.; Ahmad, I.; Abulreesh, H. H.; Althubiani, A. S. Synergistic interaction of eugenol and antimicrobial drugs in eradication of single and mixed biofilms of Candida albicans and Streptococcus mutans. AMB Express 2020, 10, https://doi.org/10.1186/s13568-020-01123-2.

38. Ahmad, A.; Khan, A.; Manzoor, N.; Khan, L.A. Evolution of Ergosterol Biosynthesis Inhibitors as Fungicidal Against Candida. Microb. Pathog 2010, 48, 35-41, https://doi.org/10.1016/j.micpath.2009.10.001.

39. Chami, N.; Bennis, S.; Chami, F.;Aboussekhra, A.; Remmal, A. Study of Anticandidal Activity of Carvacrol and Eugenol In Vitro and In Vivo. Oral Microbiol. Immunol 2005, 20, 106-111, https://doi.org/10.1111/j.1399-302X.2004.00202.X.

40. Khan, A.; Ahmad, A.; Akhtar, F.; Yousuf, S.; Xess, I.; Khan, L.A.; Manzoor, N. Induction of Oxidative Stress as a Possible Mechanism of the Antifungal Action of Three Phenylpropanoids: Antifungal Activity of Phenylpropanoids. FEMS Yeast Res 2011, 11, 114-122, https://doi.org/10.1111/j.1567-1364.2010.00697.x.

41. Baygar; Tuba; Sarac, N.; Ugur, A.; Baygar; Tacnur; Balci, U. The Inhibition Effects of Eugenol and Pulegone on Stenotrophomonas maltophilia: An Opportunistic Pathogen. Erciyes Üniversitesi Vet. Fakültesi Derg. 2019, 16, 23-29, https://doi.org/10.32707/ercivet.538021.

42. Zhang, Y.; Wang, Y.; Zhu, X.; Cao, P.; Wei, S.; Lu, Y. Antibacterial and Antibiofilm Activities of Eugenol from Essential Oil of Syzygium aromaticum (1.) Merr. \& L. M. Perry (clove) Leaf Against Periodontal Pathogen Porphyromonas gingivalis. Microb. Pathog. 2017, 113, 396-402, https://doi.org/10.1016/j.micpath.2017.10.054

43. da Costa, J. S.; da Cruz, E. de N. S.; Setzer, W. N.; da Silva, J. K. D. R.; Maia, J. G. S.; \& Figueiredo, P. L. B. Essentials oils from Brazilian eugenia and syzygium species and their biological activities. Biomolecules 2020, 10, 1-36, https://doi.org/10.3390/biom10081155.

44. Barbara D. Alexander; M.D.; MHS. CLSI. Reference Method for Broth Dilution Antifungal Susceptibility Testing of Yeasts. 4th. Edition. Clinical and Laboratory Standard Institute 2017, https://clsi.org/standards/products/microbiology/documents/m27. 
45. Pierce, C.G.; Uppuluri, P.; Tummala, S.; Lopez-Ribot, J.L. A 96 well microtiter plate-based method for monitoring formation and antifungal susceptibility testing of Candida albicans biofilms. J. Vis. Exp. JoVE 2010, https://doi.org/10.3791/2287.

46. Hamzah, H.; Tunjung Pratiwi, S.U.; Hertiani, T. Efficacy of Thymol and Eugenol Against Polymicrobial Biofilm. Indones. J. Pharm. 2018, 29, 214-221, https://doi.org/10.14499/indonesianjpharm29iss4pp214.

47. Nuryastuti, T.; Setiawati, S.; Ngatidjan, N.; Mustofa, M.; Jumina, J.; Fitriastuti, D.; Mardjan, M.I.D.. Antibiofilm activity of (1)-N-2-methoxybenzyl-1,10-phenanthrolinium bromide against Candida albicans. $J$. Mycol. Médicale. 2018, 28, 367-373, https://doi.org/10.1016/j.mycmed.2017.12.010.

48. Pratiwi, S.U.T.; Hertiani, T. Efficacy of Massoia Oil in Combination with Some Indonesian Medicinal Plants Oils as Anti-Biofilm Agent Towards Candida albicans. Int. J. Pharm. Sci. Res. 2017, 8, 2013-2025, https://doi.org/10.13040/IJPSR.0975-8232.8(5).2013-25.

49. Ali, I.; Khan, F.G.; Suri, K.A.; Gupta, B.D.; Satti, N.K.; Dutt, P.; Afrin, F.; Qazi, G.N.; Khan, I.A. In vitro antifungal activity of hydroxychavicol isolated from Piper betle L. Ann. Clin. Microbiol. Antimicrob. 2010, 9, 7, https://doi.org/10.1186/1476-0711-9-7.

50. Pratiwi, S.U.T.; Hertiani, T. Efficacy of Massoia Oil in Combination with Some Indonesian Medicinal Plants Oils as Anti-Biofilm Agent Towards Candida Albicans. Int. J. Pharm. Sci. Res. 2017, 8, 13, https://ijpsr.com/bft-article/efficacy-of-massoia-oil-in-combination-with-some-indonesian-medicinalplants-oils-as-anti-biofilm-agent-towards-candida-albicans/?view=fulltext.

51. Hess, D.J.; Henry-Stanley, M.J.; Barnes, A.M.T.; Dunny, G.M.; Wells, C.L. Ultrastructure of a Novel Bacterial Form Located in Staphylococcus aureus In Vitro and In Vivo Catheter-Associated Biofilms. $J$. Histochem. Cytochem. 2012, 60, 770-776, https://doi.org/10.1369/002215541245757.

52. Hess, D.J.; Henry-Stanley, M.J.; Barnes, A.M.T.; Dunny, G.M.; Wells, C.L. Ultrastructure of a Novel Bacterial Form Located in Staphylococcus aureus In Vitro and In Vivo Catheter-Associated Biofilms. $J$. Histochem. Cytochem. 2012, 60, 770-776, https://doi.org/10.1369/002215541245757.

53. Al-Fattani, M.A.; Douglas, L.J. Biofilm Matrix of Candida albicans and Candida tropicalis: Chemical Composition and Role in Drug Resistance. J. Med. Microbiol. 2006, 55, 999-1008, https://doi.org/10.1099/jmm.0.46569-0.

54. Olszewska, M.A.; Gedas, A.; Simoes, M. The Effects of Eugenol, Trans-Cinnamaldehyde, Citronellol, and Terpineol on Escherichia coli Biofilm Control as Assessed by Culture-Dependent and -Independent Methods. Molecules 2020, 25, 2641, 1-14, https://doi.org/10.3390/molecules25112641.

55. El-Baz, A. M.; Mosbah, R. A.; Goda, R. M.;Mansour, B.; Sultana, T.; Dahms, T. E. S.; El-Ganiny, A. M. Back to nature: Combating candida albicans biofilm, phospholipase and hemolysin using plant essential oils. Antibiotics 2021, 10, 1-18, https://doi.org/10.3390/antibiotics10010081.

56. Hamzah, H.; Hertiani, T.; Utami Tunjung Pratiwi, S.; Nuryastuti, T. The Inhibition Activity of Tannin on the Formation of Mono-Species and Polymicrobial Biofilm Escherichia coli, Staphylococcus aureus, Pseudomonas aeruginosa, and Candida albicans. Maj. Obat Tradis. 2019, 24, 110-118, https://doi.org/10.22146/mot.44532.

57. Harriott, M.M.; Noverr, M.C. Ability of Candida Albicans Mutants to Induce Staphylococcus aureus Vancomycin Resistance During Polymicrobial Biofilm Formation. Antimicrob. Agents Chemother 2010, 54, 3746-3755, https://doi.org/10.1128/AAC.00573-10.

58. de Aguiar, F. L. L.; Santos, N. C.; Cavalcante, C. S. de P.; Andreu, D.; Baptista, G. R.; Gonçalves, S. Antibiofilm activity on candida albicans and mechanism of action on biomembrane models of the antimicrobial peptide Ctn[15-34]. International Journal of Molecular Sciences 2020, 21, 1-15, https://doi.org/10.3390/ijms21218339.

59. Sharma, S.; Barkauskaite, S.; Duffy, B.; Jaiswal, A. K.; Jaiswal, S. Characterization and Antimicrobial Activity of Biodegradable Active Packaging Enriched with clove and thyme essential oil for food packaging application. Foods 2020, 9, 16, https://doi.org/10.3390/foods9081117.

60. Alexa, V. T.; Szuhanek, C.; Cozma, A.; \& Galuscan, A. Clove Essential Oils and Their Chemical Compounds. Molecules 2020, 25(23), 5502; https://doi.org/10.3390/molecules25235502

61. de Aguiar, F. L. L.; Santos, N. C.; Cavalcante, C. S. de P.; Andreu, D.; Baptista, G. R.; Gonçalves, S. Antibiofilm activity on candida albicans and mechanism of action on biomembrane models of the antimicrobial peptide Ctn[15-34]. International Journal of Molecular Sciences 2020, 21, 1-15, https://doi.org/10.3390/ijms21218339. 
62. Yadav, M.K.; Chae, S.-W.; Im, G.J.; Chung, J.-W.; Song, J.-J. Eugenol: A Phyto-Compound Effective Against Methicillin-Resistant and Methicillin-Sensitive Staphylococcus aureus Clinical Strain Biofilms. PLOS ONE. 2015, 10, e0119564, https://doi.org/10.1371/journal.pone.0119564.

63. Zhang, Y.; Wang, Y.; Zhu, X.; Cao, P.; Wei, S.; Lu, Y. Antibacterial and Antibiofilm Activities of Eugenol from Essential Oil of Syzygium aromaticum (1.) Merr. \& L. M. Perry (clove) Leaf Against Periodontal Pathogen Porphyromonas gingivalis. Microb. Pathog. 2017, 113, 396-402, https://doi.org/10.1016/j.micpath.2017.10.054.

64. Nakamura, C.V.; Ishida, K.; Faccin, L.C.; Filho, B.P.D.; Cortez, D.A.G.; Rozental, S.; de Souza, W.; UedaNakamura, T. In Vitro Activity of Essential Oil from Ocimum Gratissimum L. Against Four Candida Species. Res. Microbiol. 2004, 155, 579-586, https://doi.org/10.1016/j.resmic.2004.04.004.

65. Prakash, B.; Veeregowda, B.M.; Krishnappa, G. Biofilm: A Survival Strategy of Bacteria. Curr. Sci. 2003, 85, 1299-1307, https://www.jstor.org/stable/24108133?seq=1. 